\title{
Differentiation dependent expression of urocortin's mRNA and peptide in human osteoprogenitor cells: influence of BMP-2, TGF-beta-1 and dexamethasone
}

\author{
Mohammad Tezval · Hossein Tezval - Klaus Dresing • Ewa Klara Stuermer • \\ Martina Blaschke $\cdot$ Klaus Michael Stuermer $\cdot$ Heide Siggelkow
}

Received: 9 July 2009/Accepted: 19 November 2009/Published online: 1 December 2009

(C) The Author(s) 2009. This article is published with open access at Springerlink.com

\begin{abstract}
Urocortin-1 (UCN) a corticotropin releasingfactor (CRF) related peptide, has been found to be expressed in many different tissues like the central nervous system, the cardiovascular system, adipose tissue, and skeletal muscle. The effects of UCN are mediated via stimulation of CRFreceptors 1 and 2 (CRFR1 and 2, CRFR's) with a high affinity for CRFR2. It has been shown that the CRF-related peptides and CRFR's are involved in the regulation of stressrelated endocrine, autonomic and behavioural responses.
\end{abstract}

M. Tezval and H. Tezval contribute equally to this work.

M. Tezval $(\bowtie) \cdot$ K. Dresing $\cdot$ E. K. Stuermer · K. M. Stuermer Department of Trauma, Plastic and Reconstructive Surgery, Goettingen University Hospital, University Medicine Goetingen, Robert Koch Str. 40, 37075 Goettingen, Germany

e-mail: mtezval@med.uni-goettingen.de

K. Dresing

e-mail: klaus.dresing@med.uni-goettingen.de

E. K. Stuermer

e-mail: e.stuermer@med.uni-goettingen.de

K. M. Stuermer

e-mail: km.stuermer@med.uni-goettingen.de

H. Tezval

Department of Urology and Urological Oncology, Hannover

Medical School, Hannover, Germany

e-mail: tezval.hossein@mh-hannover.de

M. Blaschke $\cdot$ H. Siggelkow

Department of Gastroenterology and Endocrinology, University

Medicine Goettingen, Goettingen, Germany

H. Siggelkow

e-mail: hsiggel@med.uni-goettingen.de

H. Siggelkow

Department of Gastroenterology and Endocrinology,

Endokrinologikum Goettingen, Goettingen, Germany
Using immunocytochemistry, immunohistochemistry and RT-PCR, we now can show the differentiation dependent expression of UCN mRNA and peptide in human mesenchymal progenitor cells (MSCs) directed to the osteoblastic phenotype for the first time. UCN expression was down regulated by TGF-beta and BMP-2 in the early proliferation phase of osteoblast development, whereas dexamethasone (dex) minimally induced UCN gene expression during matrix maturation after $24 \mathrm{~h}$ stimulation. Stimulation of MSCs for 28 days with ascorbate/beta-glycerophosphate (asc/bGp) induced UCN gene expression at day 14. This effect was prevented when using 1,25-vitamin D3 or dex in addition. There was no obvious correlation to osteocalcin $(\mathrm{OCN})$ gene expression in these experiments. In MSCs from patients with metabolic bone disease $(n=9) \mathrm{UCN}$ gene expression was significantly higher compared to MSCs from normal controls $(n=6)$. Human MSCs did not express any of the CRFR's during differentiation to osteoblasts. Our results indicate that UCN is produced during the development of MSCs to osteoblasts and differentially regulated during culture as well as by differentiation factors. The expression is maximal between proliferation and matrix maturation phase. However, UCN does not seem to act on the osteoblast itself as shown by the missing CRFR's. Our results suggest new perspectives on the role of urocortin in human skeletal tissue in health and disease.

Keywords Urocortin - CRF related peptide . Growth factors · Osteoprogenitor cells

\section{Introduction}

Urocortin 1 (UCN) was initially described by Vaughan et al. (1995) in the rat midbrain. UCN is a 40 amino acid 
peptide related to the hypothalamic hormone corticotropinreleasing factor (CRF). The UCN peptide is $63 \%$ identical to fish urotensin and $45 \%$ identical to mammalian CRF (Latchman 2002). The effects of UCN and CRF are mediated by binding to two distinct receptors, CRFR1 and CRFR2 (Latchman 2002).

Urocortin and its related peptides such as UCN II and III are members of the corticotropin-releasing hormone (CRH) system, with a widespread tissue distribution (Bamberger et al. 2007; Boorse and Denver 2006; Sehringer et al. 2004). They are known to be relevant molecules in the management of many organ conditions and seem to play diverse roles in physiology, development and behavior in vertebrates, including suppression of appetite, regulation of anxiety, enhancement of cardiac contractility, antihypotrophic effects on skeletal muscle, vasodilatation, temperature regulation and neoangiogenesis (Boorse and Denver 2006; Latchman 2002; Vaughan et al. 1995). Many studies have shown the relevant effects of CRF-related peptides such as UCN in stress responses. One of the interesting aspects of UCN function is its role in the regulation of neuropeptide Y (NPY) and leptin in adipose tissue and energy balance (Fekete et al. 2002). Besides their expression in brain, UCN and the CRFRs have been identified at multiple peripheral sites. UCN-related peptides seem to be relevant in the pathogenesis of diverse conditions, e.g., hypertension, congestive heart failure, rheumatoid arthritis, food intake, spontaneous abortion and atopic/allergic disorders (Bale et al. 2004; Fekete and Zorrilla 2007). Recently, possible effects of UCN were reported on proliferation during cell growth, differentiation, cell repair, apoptosis and cancer (Ikeda et al. 2002; Slominski et al. 2006).

The expression of genes and proteins during osteoblast development and transcriptional regulation of these genes is of essential importance in the regulation of osteoblast differentiation and function (Hughes et al. 2006). In this study, we investigated UCN expression at the mRNA and peptide levels, in addition to the expression of CRFRs, during osteoblastic differentiation of mesenchymal progenitor cells and examined possible regulatory effects of growth factors on UCN gene expression.

\section{Materials and methods}

\section{Cell culture}

Bone specimens were obtained from the iliac crest of 5 patients (4 women, 1 man; age $36.2 \pm 5.2$ years) undergoing corrective surgery after traumatic fracture. None of the patients had signs or symptoms of bone or autoimmune diseases. The study was approved by the
Institutional Review Board of the University of Goettingen. Following written informed consent, we obtained RNA from both primary and second passage mesenchymal progenitor cells from cultures of trabecular bone explants as previously described (Siggelkow et al. 1999). Additional experiments revealed the mesenchymal origin of the cells. When stimulated accordingly, the cells differentiated into adipocytes, chondrocytes and osteoblasts. With FACS analysis of surface antigens, the cells showed a profile consistent with a mesenchymal origin (mean \pm SD of three donors): CD45: $4.7 \pm 2.9 \%$, CD $34: 4.0 \pm 2.6 \%$ (hematopoietic origin) CD44: $10.6 \pm 4.8 \%, \quad \mathrm{CD} 90$ : $93.7 \pm 5.6 \%$, CD105: $34.9 \pm 20.2 \%$ (mesenchymal stem cell markers) (Ponce et al. 2008). Therefore, the cells formerly referred to as preosteoblasts were multipotent and were thus termed mesenchymal progenitor cells or trabecular bone-derived mesenchymal stem cells (MSCs) (Ponce et al. 2008).

MSCs were grown out of explants, maintained in medium (DMEM with 10\% fetal calf serum (FCS), glutamine $(58.5 \mu \mathrm{g} / \mathrm{ml})$, penicillin $(100 \mathrm{U} / \mathrm{ml})$, and streptomycin $(100 \mu \mathrm{g} / \mathrm{ml}))$, at $37^{\circ} \mathrm{C}$ in a humidified $95 \%$ air $/ 5 \% \mathrm{CO}_{2}$ atmosphere described as basal conditions as from now. Cultures were initiated within 3 hours of receiving the bone chips and fed twice a week. Initial assessment of UCN expression was performed under established culture stimulation with beta-glycerophosphate (bGp, $10 \mathrm{mM}$, Sigma, Taufkirchen, Germany) and ascorbate (asc, $50 \mu \mathrm{g} / \mathrm{ml}$, sigma, Taufkirchen, Germany). Differentiation-dependent gene expression was investigated in a human model of osteoblast differentiation initially described for rat osteoblasts by Owen and colleagues (Owen et al. 1990) and confirmed by us in the human model using stimulation with an identical concentration of bGp and asc in addition to dexamethasone (dex, $10^{-8} \mathrm{M}$, Sigma, Taufkirchen, Germany) (Siggelkow et al. 2004). For this experiment cell confluence of first passage cells plated at a density of $2 \times 10^{5}$ cells per well was reached between days 10 and 12 when the experiment started. Day 28 in culture therefore represents day 28 after confluence. The differentiation sequence in this model is characterized by the three phases, proliferation, matrix maturation and mineralization (Owen et al. 1990). In addition we analyzed UCN gene expression during 28 days in MSCs stimulated beginning at confluence with control compared to asc in combination with bGp, asc in combination with bGp and 1,25-vitamin D3 $\left(5 \times 10^{-8} \mathrm{M}\right)$, furthermore asc, bGp and dex using the former concentrations and finally all four components combined. To obtain a sufficient number of cells for this experiment, cells of third passage were used. Cells were plated at $10^{5}$ cells/well, grown until confluence with $10 \%$ FCS, switched to $1 \%$ human serum for 3 days when the experiment started for 28 days. 
Furthermore, we examined the possible influence of different growth factors on UCN expression using standard concentrations of differentiating agents. MSCs in the second passage were cultured for 28 days using basal conditions without any differentiation factors. Cells therefore represent MSCs not directed to the osteoblastic phenotype (Siggelkow et al. 1999). For the final 24 hours, the different factors were added separately to the medium in comparison to $0.1 \% \mathrm{BSA}$ and solvent. For this experiment, BMP-2 (50 ng/ml, PromoCell, Heidelberg), TGF-beta $(1 \mathrm{ng} / \mathrm{ml}$, PromoCell, Heidelberg), and dex $\left(10^{-8} \mathrm{M}\right)$ were used for $24 \mathrm{~h}$ on days 4,14 and 28.

\section{Real-time PCR}

Real-time PCR was performed using a Mastercycler Eppendorf Realplex ${ }^{2}$ detection system with Mastercycler ep gradients software. Reactions were set up in 96-well plates using the following concentrations: $0.2 \mu \mathrm{M}$ of each sense and antisense primer for target genes (see below), $4.5 \mu$ Platinum Sybr Green qPCP superMix-UDP (Invitrogen) and $1 \mu \mathrm{l}$ cDNA I (250 ng mRNA) in a $10 \mu \mathrm{l}$ reaction volume. A two-step amplification protocol was chosen, with initial denaturation at $95^{\circ} \mathrm{C}$ for $2 \mathrm{~min}$, followed by 40 cycles with $15 \mathrm{~s}$ denaturation at $95^{\circ} \mathrm{C}, 15 \mathrm{~s}$ annealing at $60^{\circ} \mathrm{C}$ and $20 \mathrm{~s}$ extension at $68^{\circ} \mathrm{C}$. Finally, a dissociation protocol was performed to control for specificity of amplification products. For time course expression, the amount of PCR product was measured relative to the expression of the housekeeping gene EEF1A1 [housekeeping genes, as previously described (Siggelkow et al. 1999, 2004)] analyzed by the threshold-cycle $\left(C_{t}\right)$ method. The specificity of $\mathrm{PCR}$ products was confirmed by sequencing (Seqlab, Goettingen. Germany). The same procedure was used to detect the CRFR's (1 and 2) mRNA with known sense and antisense primers as previously described (Kimura et al. 2002; Nazarloo et al. 2006; Sehringer et al. 2004; Tezval et al. 2009b; Table 1).

Preparation for immunocytochemical (ICC) and immunohistochemistry staining

The initial step of the ICC procedure involved pre absorption of the eight-chamber tissue culture slides with FCS free of gamma globulin (GG-free) (45 min, RT). This was followed by incubations with the first $(1: 50,1: 100)$ and then the second antibody (1:50) (each for $60 \mathrm{~min}, \mathrm{RT}$ ). The latter was conjugated with FITC and pre absorbed (60 min, RT) with human sera. The cells were mounted with Fluoromount (Southern Biotechnology, Birmingham, England)/1,4diazabicyclo-2.2.2.-octane (DABCO) $(200 \mathrm{mg} / \mathrm{ml})$ (Aldrich Chemicals, Steinheim, Germany). Results were documented on Ectachrome Elite 400 (Eastman Kodak, Rochester, NY, U.S.A.) using the immunofluorescence microscope Orthoplan (filter L3 533670, objectives: NPL Fluostar 40/1.30 oil and 170/2 10/0.45 oil) (Leitz, Wetzlar).

The immunofluorescence analysis with 4',6-Diamidino2-phenylindol staining (DAPI) were carried out as previously described for UCN expression in MSCs stimulated to the osteoblastic phenotype with bGp, asc and dex (Tezval et al. 2009a).

Renal tissue was selected for immunohistochemical staining. The tissue was fixed in $4 \%$ buffered formalin and embedded in paraffin. Serial sections of $5 \mu \mathrm{m}$ were cut from paraffin blocks, mounted on APES-coated slides, deparaffinized in xylene and rehydrated in graded alcohol to PBS (50 mM Tris, $150 \mathrm{mM} \mathrm{NaCl}, \mathrm{pH} 7.4$ ). The slides were microwaved for $4 \times 3 \mathrm{~min}$ in $10 \mathrm{mM}$ citrate, $\mathrm{pH}$ 6.0. After cooling, slides were washed in PBS, blocked for $30 \mathrm{~min}$ at room temperature with normal goat serum and incubated with Anti-UCN serum (Abcam). Immunoreactivity was detected with the standard ABC protocol. For negative controls, the same procedures were done in absence of primary antibody. Moreover, incubation of synthetic UCN with an antibody against UCN abolished the observed signals and demonstrated the specificity of the documented immunoreactivity for UCN. Renal tissue was used as positive control because of known expression of UCN (Tezval et al. 2009a). The stained renal tissue was analyzed using confocal microscopy (for better analysis of stained proximal tubuli).

Analysis of MSCs from patients with metabolic bone diseases

We studied MSCs from nine patients aged 24-73 years (median age 55 years, mean $52.4 \pm 15.4$ years; five male, four female) with metabolic bone diseases of different origins who had been referred for bone biopsy, as published previously (Siggelkow et al. 2003). All patients had a preliminary diagnosis of either osteopenia (3 patients) or osteoporosis (6 patients.) according to WHO criteria. All patients gave informed consent and the study was approved by the ethics committee of Goettingen University Medical Center. Bone biopsies from the iliac crest were divided into two parts; one was used for histomorphometric evaluation and the other for initiation of MSC cultures as described (Siggelkow et al. 2003, 2004). The final diagnosis based on histomorphometry, were primary osteoporosis of varying severity $(n=5)$, steroid osteoporosis $(n=1)$ and mild intestinal osteopathy ( $n=3$ ) (Siggelkow et al. 2003).

We also studied primary MSC cultures from six subjects who underwent operations due to trauma or plastic surgery without evidence of any bone or joint disease (mean age $58 \pm 12.7$ years). Bone material was taken either from the 
Table 1 Primers used for RTPCR analysis

\begin{tabular}{|c|c|c|c|}
\hline Genes & Primer & bp & References \\
\hline $\mathrm{UCN}$ & $\begin{array}{l}\text { Sense: } 5^{\prime} \text {-CGAGCAGAACCGCATCATATT-3' } \\
\text { Antisense: } 5^{\prime} \text {-ACAGTGCCCTGGTGGCTCT-3' }\end{array}$ & 123 & Bamberger et al. (2007) \\
\hline CRFR1 & $\begin{array}{l}\text { Sense: 5'-CAACAATGGCTACCGGGAG-3' } \\
\text { Antisense: 5'-ACACCCCAGCCAATGCAGA-3' }\end{array}$ & 66 & Sehringer et al. (2004) \\
\hline CRFR 2 & $\begin{array}{l}\text { Sense: 5'-GTACAGGAAGGCAGTGAAG-3' } \\
\text { Antisense: 5'-AAGACAGACACGAAGAAACC-3' }\end{array}$ & 66 & Sehringer et al. (2004) \\
\hline $\mathrm{OCN}$ & $\begin{array}{l}\text { Sense: } 5^{\prime} \text {-CATGAGAGCCCTCACA-3' } \\
\text { Antisense: } 5^{\prime} \text {-AGAGCGACACCCTAGAC-3' }\end{array}$ & 310 & Ponce et al. (2008) \\
\hline Beta-actin & $\begin{array}{l}\text { Sense: 5'-CTGGAACGGTGAAGGTGACG-3' } \\
\text { Antisense: 5'- AGTCCTCGGCCACATTGTGA-3' }\end{array}$ & 70 & Ponce et al. (2008) \\
\hline EEF1A1 & $\begin{array}{l}\text { Sense: 5'-AGGTGATTATCCTGAACCATCC-3' } \\
\text { Antisense: 5'-AAAGGTGGATAGTCTGAGAAGC-3' }\end{array}$ & 234 & Ponce et al. (2008) \\
\hline
\end{tabular}

iliac crest or from the tibia plateau. Cells from bone diseased patients and these healthy controls were grown to near confluence using highly standardised conditions and fed twice a week. Cells were also fed $24 \mathrm{~h}$ before analysis. After 5 to 6 weeks ( $39 \pm 7.7$ days), primary culture cells were harvested with guanidine isothiocyanate for mRNA analysis.

\section{Statistical analysis}

Statistical analysis of control and stimulated levels was performed with the Kruskal-Wallis test for significance between all groups. $P<0.05$ was considered significant (GraphPad Prism version 3.0).

\section{Results}

In this work, we investigated the developmental, gene and peptide expression of UCN. Apart from the influence of time, we examined several cofactors known to play important roles during osteoblast differentiation.

Tissue specific gene expression

Using reverse transcriptase PCR analysis we showed the UCN gene expression in MSCs after incubation with bGp and asc. Human heart cells served as positive control due to the known high expression of UCN (Fig. 1). The analyzed cells were from day 39 of MSC culture.

\section{Detection of CRFRs}

As shown in the Fig. 1, we did not find any CRFRs in the osteoblast culture. As positive control we used heart tissue with known expression of CRFR1 and CRFR2. The detection of the CRFRs was performed under the same conditions and cultures used for the investigation of UCN expression (as described above).

Expression of UCN mRNA by MSCs directed to the osteoblastic phenotype

We could show time- and stimulation-dependent expression of UCN mRNA in cell culture directed to an osteoblastic phenotype (Fig. 2a). UCN gene expression increased by 2 fold to its maximum at day 14 during the matrix maturation stage according to the differentiation model (Fig. 2b) described by Owen et al. and Siggelkow et al. (Owen et al. 1990; Siggelkow et al. 1999) after stimulation with bGp/asc/dex $(P<0.05)$. The decrease in expression during the mineralization phase was not significant (Fig 2a). To further investigate the influence of osteogenic differentiation on UCN gene expression we investigated UCN expression in an experiment with four different media (Fig. 3). Using only basal conditions there was no increase in osteogenic differentiation as shown by basal osteocalcin (OCN) levels, a characteristic marker of the late osteoblastic phenotype (Fig. 3e-h, open circle). When asc and bGp were added, OCN gene expression increased to 1.5 fold levels (Fig. 3e, filled square). This only slight increase in osteoblastic phenotype paralleled a 3 fold increase of UCN expression as early as day 7 in culture, with a decrease to basal levels thereafter besides increasing osteoblastic phenotype (Fig. 3a, filled square). This increase was still detectable when 1,25-vitamin D3 was added in addition but the variation was higher (Fig. 3b, filled square). When dex was added the increase was not detectable any more (Fig. 3c, filled square), UCN expression even decreased to nearly $50 \%$ from day 0 to day 7 , an effect even stronger when asc, bGp, 1,25-vitamin 
Fig. 1 Gene expression of UCN by PCR in human mesenchymal progenitor cells (MSCs) directed to the osteoblastic phenotype after incubation with bGp/asc (upper picture). Under the same culture conditions the MSCs die not express any CRFRs. Human heart cells were used as positive control, because of known expression of UCN and CRFRs (lower picture)
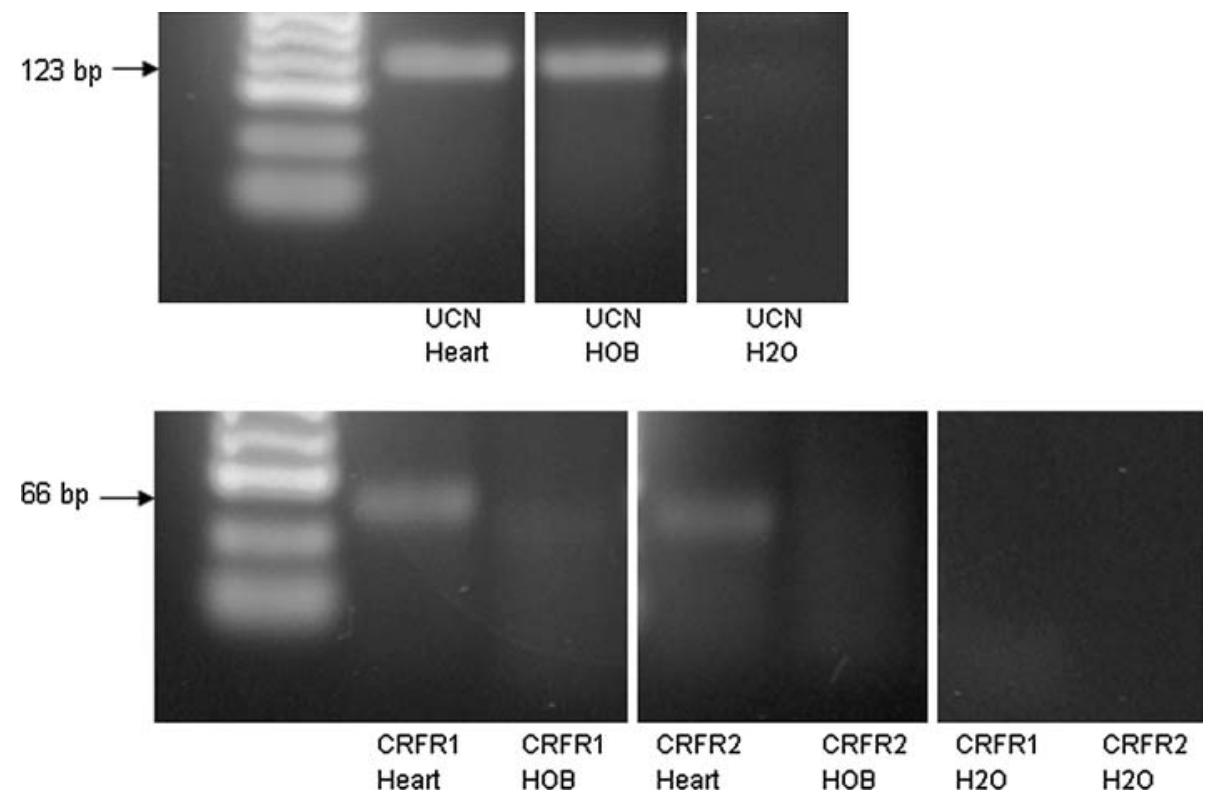

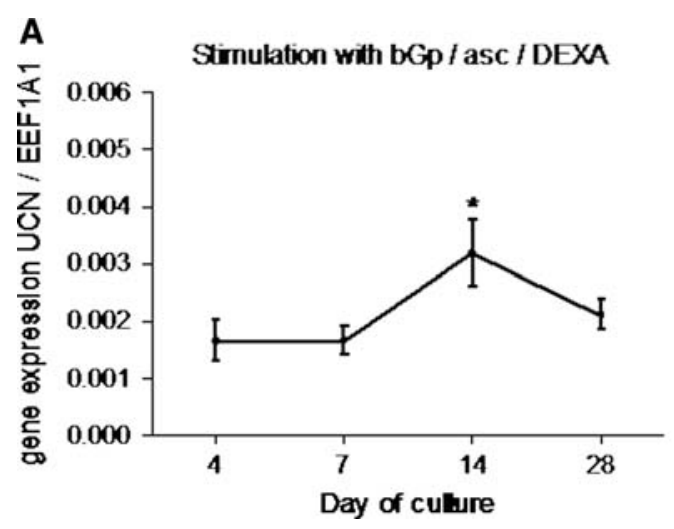

Fig. 2 a Gene expression of UCN in primary human osteoblasts after incubation at confluence with $\mathrm{bGp} / \mathrm{asc} / \mathrm{dex}(* P<0.05$ vs. day 4,7 and 28). Mean $\pm \operatorname{SEM}(n=5)$ analysed by RT-PCR, as described in methods. b A comparison between the differentiation model as proposed by Owen in rat osteoblasts and confirmed by Siggelkow in

D3 and dex were added without any difference compared with control conditions (Fig 3d, filled square). These results show an increase of UCN using bGp and asc and a decrease when osteoblastic differentiation proceeded. However, UCN gene expression did not correlate with OCN, which was stimulated 500 fold by the addition of 1,25-vitamin D3 and 2,000 fold after 28 days in culture proving the osteoblastic phenotype (Fig. $3 F$, filled square). Using dex in addition to asc and bGp decreased OCN gene expression levels to $24 \%$ already at day 7 in culture (Fig. 3g, filled square). Dex in addition to 1,25-vitamin D3 prevents the final increase in OCN expression (Fig 3h, filled square).

Also, in mesenchymal progenitor cells grown for 28 days without any osteoblastic stimulation, expression of
B

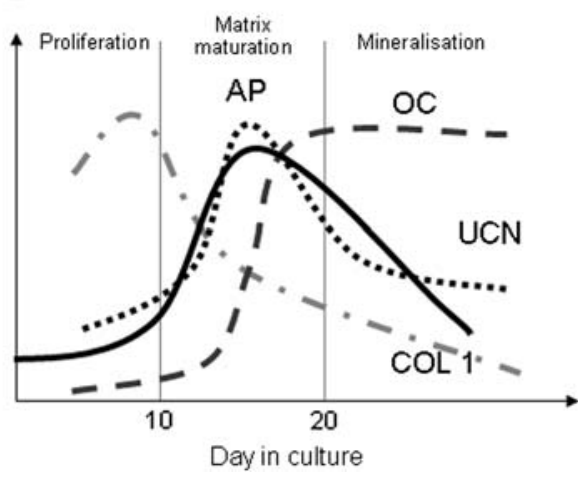

the human system and UCN gene expression after stimulation with $\mathrm{bGp} / \mathrm{asc} / \mathrm{dex}$ shows that the maximum of these expression occurred in the matrix maturation stage. It is important to mention that this is a schematic comparison for better understanding the differentiation phase of urocortin-expression

UCN decreased to about $15 \%$ from day 4 to day 28 (Fig. 5, left column, co day 4, co day 14 , co day 28 ). Because these cells were not stimulated to the osteoblastic phenotype the spontaneous differentiation of these cells coincide with a decrease in UCN expression.

Immunocytochemistry and immunofluorescence analysis

After 4, 14 and 28 days, we labeled the cells in culture immunocytochemically (fluorescence microscopy for cells from day 14 and 28). The cells in culture stained positive for UCN with low intensity in the cytosolic area in both immunostaining tests. The staining intensity decreased from day 14 to day 28 in parallel to UCN 
Fig. 3 Gene expression by realtime PCR of urocortin (UCN, a-d) and osteocalcin ( $\mathrm{OCN}$, e-h) in MSCs stimulated for 28 days beginning 3 days after confluence. Control cells were fed with $1 \%$ human serum. For stimulation ascorbate (asc) and beta-glycerophoshate (bGp) were used either alone $(\mathbf{a}, \mathbf{e})$, or in combination with 1,25vitamin D3 (D3, b, f) or dexamethasone (dex, $\mathbf{c}, \mathbf{g}$ ) or D3 and dex $(\mathbf{d}, \mathbf{h})$. UCN and OCN are depicted relative to the housekeeping gene beta-actin. Values at day 0 were arbitrarily put to 1 , therefore the presented data show relative changes in gene expression. Differences between control and stimulated cultures were analysed by Kruskal-Wallis test $(* P<0.05, * * P<0.01)$
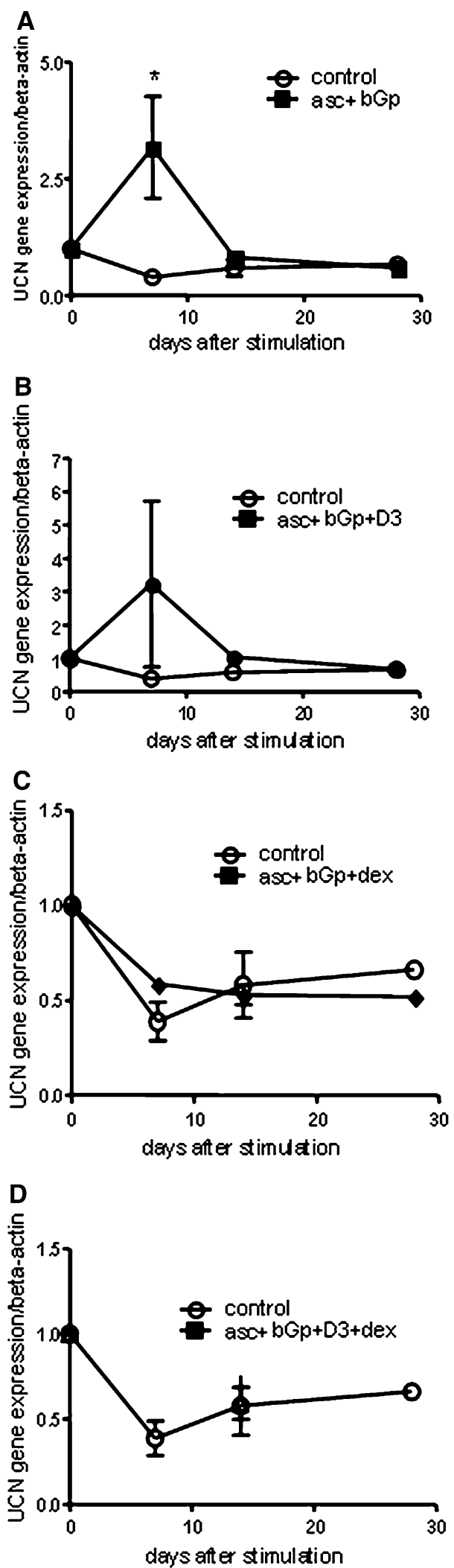
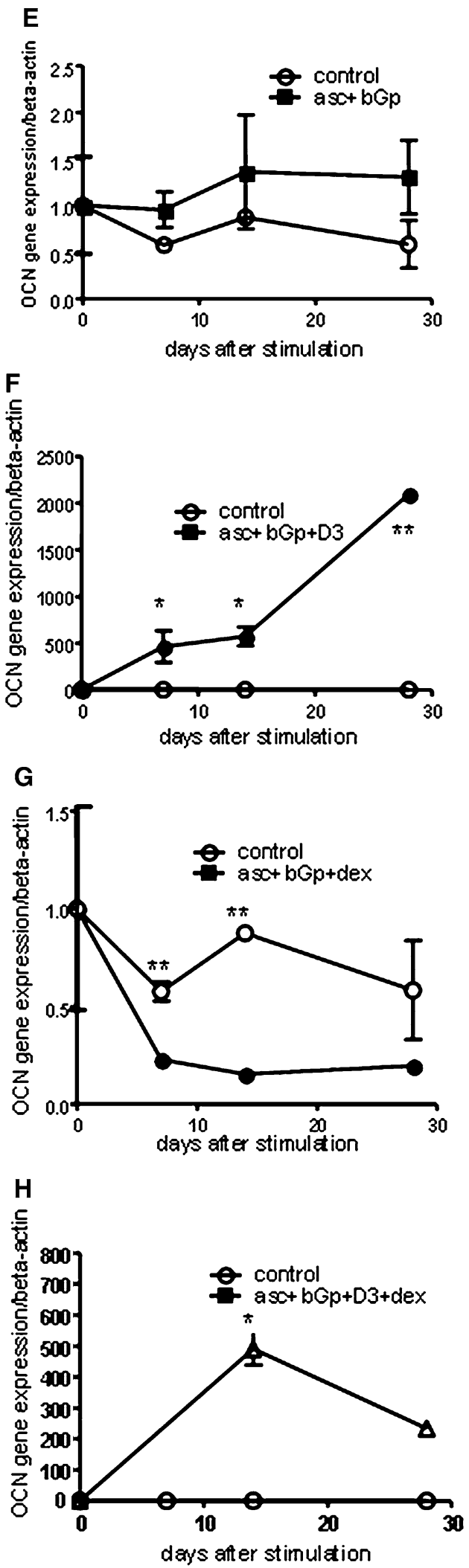

gene expression (Fig 4a-i). Nonspecific staining was excluded by omission of the primary antibody. Interestingly, UCN showed an inhomogeneous nuclear staining with differing intensities in some cells after DAPI staining (Fig 4e, h). As a further positive control we stained the renal tissue (immunohistochemistry) with 

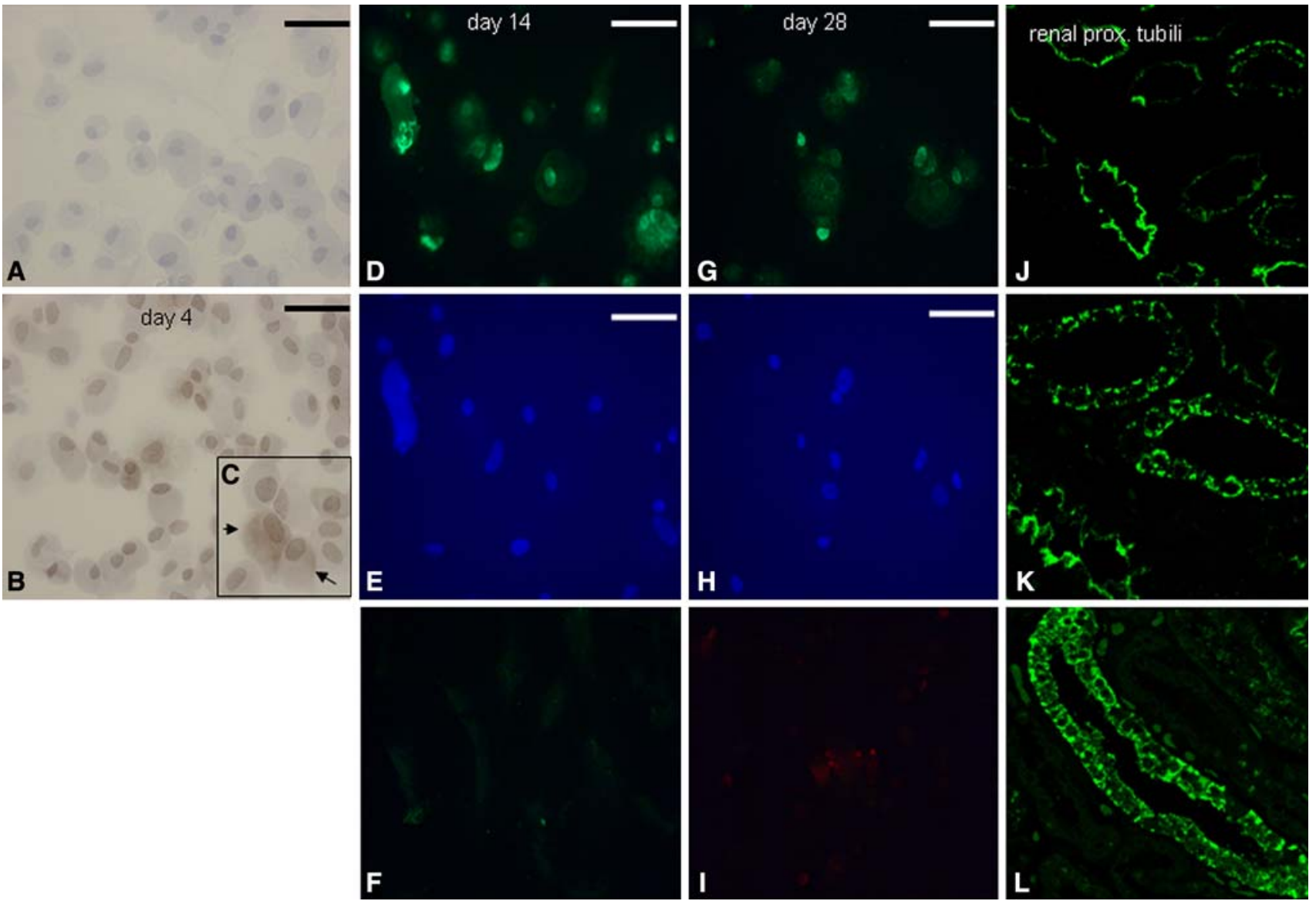

Fig. 4 Immunocytochemistry, immunofluorecsence and DAPI staining $(400 \times$ magnification). Osteoblasts in the cell culture stained positive for UCN after stimulation with $\mathrm{bGp} / \mathrm{asc} / \mathrm{dex}$. a Control cells (unstained), b Immunocytochemically stained cells for UCN (day 4). c The arrows show the stained cytoplasma of cells in the same culture. d, $\mathbf{g}$ UCN shows a cytoplasmic staining in the immunofluorecsence (IF) analysis (D = day $14, \mathrm{G}=$ day 28 ). e, h Interestingly, UCN shows also an inhomogeneous nuclear staining with differing

known high expression of $\mathrm{UCN}$ in proximal tubuli (Fig 4j-1).

\section{Influence of growth factors on UCN expression}

We investigated the possible regulatory effects of different growth factors on UCN expression by adding these factors separately to the medium. This is a relative artificial situation, because cells were not stimulated osteogenically before treatment and in a normal environment all factors would act in common. But this experiment can reveal the short time effect of single factors. The results of this experiment are shown in Fig 5.

To assess the effects of TGF-beta (1 ng/ml), BMP-2 $(50 \mathrm{ng} / \mathrm{ml})$, and $\operatorname{dex}\left(10^{-8} \mathrm{M}\right)$ on UCN mRNA expression, we treated MSCs with either vehicle $(0.1 \%$ BSA with $0.001 \%$ ethanol as solvent) or agent in time course intensities in some cells (DAPI staining, $\mathrm{E}=$ day $14, \mathrm{H}=$ day 28). Bars $=27 \mu \mathrm{m}$. F, I: To proof the specificity of this finding, the antiUCN antibodies were incubated over-night with synthetic human UCN prior to application in IF ( $\mathrm{F}=$ day $14, \mathrm{I}=$ day 28$)$. This pretreatment completely eliminated the UCN signal, confirming the specificity of our UCN detection method. $\mathbf{j}-\mathbf{l}$ Renal proximal tubuli were stained for UCN as positive controls (confocal microscopy)

experiments. Both, BMP-2 and TGF-beta resulted in significant $(P<0.005)$ down regulation of UCN mRNA on day 4 of culture. TGF-beta led to an initial decrease of approximately $76 \%$ of UCN mRNA on day 4 . UCN gene expression was about $85 \%$ suppressed by BMP-2 after 4 days. After 14 days, the effects by BMP-2 and TGFbeta were weaker, and no significant effect of these growth factors was detectable at day 28. In contrast, dex treatment had no effect on UCN expression on day 4 but resulted in a significant increase in UCN expression later in culture (14 and 28 days). These results show a time dependent expression of UCN in MSCs and in addition, a differential regulation by growth factors. The UCN expression was sensitive to TGF-beta and BMP-2 early in culture and responsive to dex later in differentiation, however with a reciprocal effect on UCN expression in MSCs. 


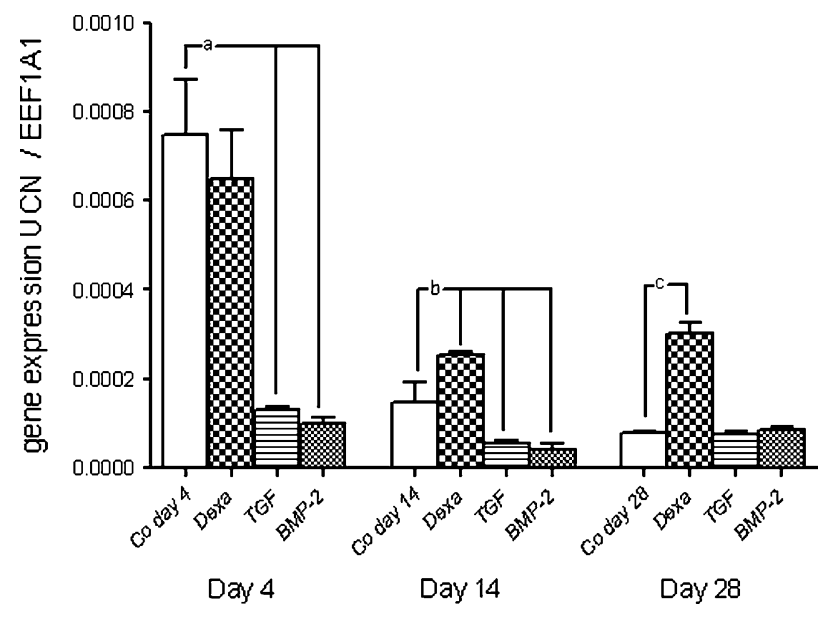

Fig. 5 Gene expression of UCN in MSCs after $24 \mathrm{~h}$ incubation on day 4, day 14 and day 28 with single osteogenic factors [TGF-beta-1 $(1 \mathrm{ng} / \mathrm{ml})$, BMP-2 $(50 \mathrm{ng} / \mathrm{ml})$, or dexamethasone $\left.(\operatorname{dex})\left(10^{-8} \mathrm{M}\right)\right]$ compared to control $(0.1 \%$ BSA with solvent). Mean $\pm \operatorname{SEM}(n=4)$ analyzed by RT-PCR, as described in methods. Values were normalized to the housekeeping gene EEF1A1 and presented as percentage of the maximum expression of each gene. $a-P<0.01$, $b-P<0.05$ and $c-P<0.01$ versus control are significant as calculated by Kruskal-Wallis-test. There is a decrease in basal expression of UCN from day 4 to day 28 (white bar). At day 4 the inhibition of UCN expression by TGF-beta and BMP-2 is highly significant, the effect is less on day 14 and not detectable late in culture. In contrast, dex had no effect early at day 4, but an increase beginning at day 14 with the maximum effect on day 28

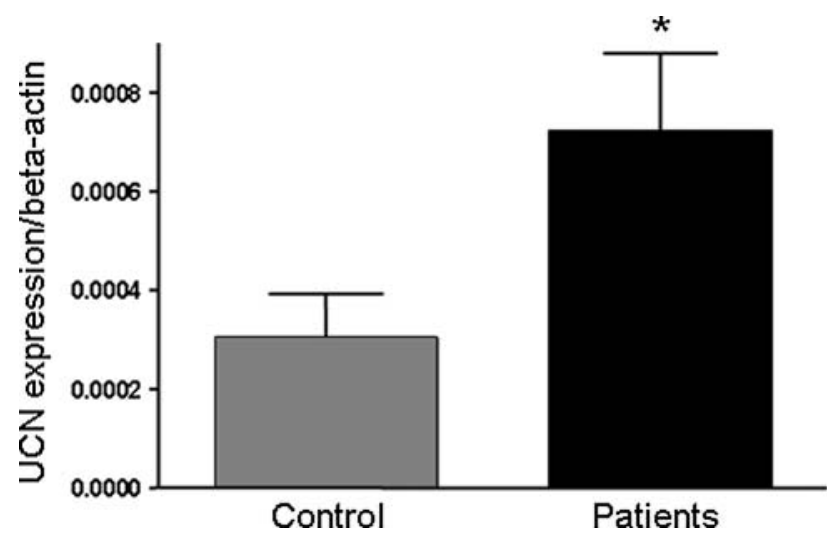

Fig. 6 Real-time PCR measuring the expression of UCN in relation to a housekeeping gene (beta-actin) in primary cultures of MSCs established from patients with metabolic bone diseases $(n=9)$ and healthy controls $(n=6)$, grown under standard conditions without differentiation factors. Differences between the two groups were analysed by Kruskal-Wallis test $(* P<0.05)$

UCN gene expression in MSCs from patients with metabolic bone diseases compared to controls

There was significant 2.3 fold higher UCN gene expression in patients with osteopenia or osteoporosis compared to control patients as revealed by RT-PCR (Fig 6).

\section{Discussion}

Urocortin1 (UCN) is a member of the corticotropinreleasing hormone ( $\mathrm{CRH}$ )-related peptides family and is found in many peripheral tissues and cells. This peptide seems to have several effects in different tissues (Slominski and Wortsman 2000). UCN has been reported to have significant effects on cell differentiation and may play a role in cell proliferation, differentiation and apoptosis via receptor-mediated (CRFR1, CRFR2) actions in several organ systems such as the CNS, heart, skeletal muscle, bowel, uterus, skin and adipose tissue (Carlson et al. 2001; Ikeda et al. 2002; Slominski et al. 2006).

Bone cells constantly receive signals from surrounding cells and tissues, and also from distant organs, e.g., via hormones and growth factors, that regulate their proliferation, activity and survival (Xing and Boyce 2005). Understanding the mechanisms and regulation of mesenchymal cell proliferation, differentiation towards the osteoblastic phenotype, and apoptosis will enhance our knowledge of bone cell function and help us to develop better therapeutics for the treatment and management of bone diseases.

With the present study, we demonstrate for the first time that UCN mRNA and protein are expressed by MSCs directed to the osteoblastic phenotype. The absolute level of expression was donor-dependent. The differentiationand time-dependent expression and regulation by growth factors confirm the functional relevance of UCN in bone. Interestingly in some cells in culture, UCN showed not only a cytoplasmic but also a nuclear positive staining with differing intensities. As a 40 amino acid peptide, it is likely that UCN can passively pass the nuclear envelope and pores, and this may even apply to the UCN precursor (26 kD). Open questions include whether there is a yet unidentified carrier protein involved in an active transport of UCN into the nucleus and which function can here result (Tezval et al. 2009a). It is here important to mention, that the low gene expression of UCN does not correlate or correspond necessarily with protein expression. It is well possible that the protein expression is different during further differentiation and proliferation. Future investigations are needed to determine such changes and correlations between gene and protein expression of UCN.

According to the model of developmental stages of osteoblast differentiation first described by Owen et al. (Owen et al. 1990), we saw UCN expression mainly during the proliferation and matrix maturation stages. UCN expression was dependent on the differentiation stage of the osteoblast, with decreasing levels with increasing OCN expression. To our surprise asc in combination with bGp was a potent inducer of UCN gene expression. bGP is used in osteoblastic stimulation as a phosphate donor to induce 
mineralization. We showed a dose dependent increase in OCN expression using concentration between 2.5 and $20 \mathrm{mM}$ (Siggelkow et al. 1999, 2004). Asc is essential for the secretion of collagen from the osteoblastic cells and, therefore, is the main inducer of matrix synthesis as a prerequisite for mineralization (Siggelkow et al. 1999, 2004). These results, at least the gene expression data, would attribute to UCN a role at the beginning or during matrix synthesis of osteoblastic cells.

Because cytokines and growth factors significantly influence the proliferation and differentiation properties of bone cells, we previously studied Cbfa1/Runx 2 and OCN as target genes for regulation by TGF-beta, BMP-2 and dex (Viereck et al. 2002). Because of their known expression behavior after stimulation with different growth factors, a comparison between these known markers and UCN expression provided a better understanding of the UCN expression time course in MSC culture. During the early stages of bone formation, the role of TGF-beta is to recruit and stimulate osteoprogenitor cells to proliferate, providing a pool of early osteoblasts (Hughes et al. 2006). BMP-2 has a key role during osteoblast commitment and differentiation, but it also seems to regulate the terminal differentiation and mineralization phases and up regulate the expression of OCN (Rickard et al. 1994). TGF-beta suppressed adipogenic differentiation of MSCs whereas BMP2 promoted the osteoblastic and adipogenic phenotype in parallel (Ponce et al. 2008). During the early phase of osteoblast differentiation, BMP-2 suppressed OCN (Viereck et al. 2002), suggesting a possible induction of proliferation. In our work TGF-beta and BMP-2, besides their differential effect on the osteoblastic phenotype, both decreased UCN gene expression early in culture beginning at day 4 . The effect was still evident at day 7 but with lower levels of basic expression at day 14 the effect could no longer be detected. Hence, from these data the induction of proliferation seems to be accompanied by a decrease in $\mathrm{UCN}$ expression. This would suggest for UCN a role after proliferation in the more differentiated osteoblast. This interpretation is supported by our results using asc and bGp showing a role in the matrix maturation phase. In addition, our immunocytochemical results suggested a time-dependent decrease in UCN peptide induced by TGF-beta, BMP2 and dex late in culture using identical conditions (Viereck et al. 2002), whereas UCN expression was decreased early in culture by TGF-beta and BMP-2. In addition, UCN gene expression was increased by short time incubation with dex alone late in culture. The reciprocal influence of these important factors, which regulate bone cell differentiation and development, also suggests a role for UCN in bone.

To further strengthen our hypothesis we investigated UCN gene expression in MSC cultures derived from patients and compared them to those from healthy controls.
The expression in MSCs from patients with metabolic bone diseases was significantly higher. MSCs derived from patients reflect different properties of the original cells in the patients, shown for proliferation, osteoblast formation and activity (Marie et al. 1989, 1993). Hence, the higher UCN expression in patients with metabolic bone diseases could possibly be regarded as a change in osteoblastic function further supporting a role for UCN in bone.

It is known that the UCN gene and peptide are able to influence skeletal muscle, the vascular system, and fat tissue and are also involved in stress responses and food intake. This influence is in part due to vasodilatation, an antihypotrophic effect on skeletal muscle, insulin and temperature regulation in skeletal muscle, energy balance and many other effects mainly via the CRFR2 receptor (Bale et al. 2002; Hinkle et al. 2004; Isfort et al. 2005). Interestingly, Kotz et al. (2002) used a rat model to show that UCN in the hypothalamic paraventricular nucleus (PVN) was able to increase leptin and affected uncoupling poteins- 1 and -3 . The findings of Bouxsein et al. could also suggest a positive effect of weight and leptin on bone turn over and cortical bone structure in mouse (Bouxsein et al. 2009; Caetano-Lopes et al. 2007). Therefore an interaction between UCN and leptin concerning an effect on bone formation and resorption is quite possible. No information exists on similar effects of UCN in the human system.

We did not find any CRFRs during osteoblast differentiation under the conditions used in our study. We assume that UCN does not have an autocrine function, but instead has a paracrine or endocrine function in this system. There might be a possible interaction between UCN expression in bone cells and adjacent tissues known to express CRFreceptors such as bone marrow (e.g., monocyte-macrophage system and mast cells), muscle, the vascular system and fat tissue. During osteoblast proliferation and/or differentiation, UCN might act in a paracrine and/or endocrine manner. Kageyama et al. previously found that both UCN and UCN 2 induced the accumulation of intracellular cAMP via CRFR2 binding and significantly increased IL-6 secretion by aortic smooth muscle cells (Kageyama et al. 2006), suggesting an important effect on vascular system and inflammation. IL-6 is a known pleiotropic cytokine with variety of biological activities and proinflammatory effects.

\section{Conclusion}

In summary, we found differentiation- and time dependent expression of UCN mRNA and detected its peptide in MSCs directed to the osteoblastic phenotype. Furthermore, UCN gene expression was regulated by important growth factors. With regard to the known effects of UCN on cell 
differentiation and proliferation in other tissues, it can be speculated that UCN may also play an important role in the interaction between bone, central nervous system and surrounding tissues such as bone marrow, fat and the vascular system.

Acknowledgments The authors thank F. Kauer, R. Castro, A. Witt, and R. Köpp for their technical support. We thank Hoffmann-LaRoche for supplying 1,25-vitamin D3.

Open Access This article is distributed under the terms of the Creative Commons Attribution Noncommercial License which permits any noncommercial use, distribution, and reproduction in any medium, provided the original author(s) and source are credited.

\section{References}

Bale TL, Giordano FJ, Hickey RP, Huang Y, Nath AK, Peterson KL, Vale WW, Lee KF (2002) Corticotropin-releasing factor receptor 2 is a tonic suppressor of vascularization. Proc Natl Acad Sci USA 99:7734-7739

Bale TL, Hoshijima M, Gu Y, Dalton N, Anderson KR, Lee KF, Rivier J, Chien KR, Vale WW, Peterson KL (2004) The cardiovascular physiologic actions of urocortin II: acute effects in murine heart failure. Proc Natl Acad Sci USA 101:3697-3702

Bamberger CM, Minas V, Bamberger AM, Charalampopoulos I, Fragouli Y, Schulte HM, Makrigiannakis A (2007) Expression of urocortin in the extravillous human trophoblast at the implantation site. Placenta 28:127-132

Boorse GC, Denver RJ (2006) Widespread tissue distribution and diverse functions of corticotropin-releasing factor and related peptides. Gen Comp Endocrinol 146:9-18

Bouxsein ML, Devlin MJ, Glatt V, Dhillon H, Pierroz DD, Ferrari SL (2009) Mice lacking beta-adrenergic receptors have increased bone mass but are not protected from deleterious skeletal effects of ovariectomy. Endocrinology 150:144-152

Caetano-Lopes J, Canhao H, Fonseca JE (2007) Osteoblasts and bone formation. Acta Reumatol Port 32:103-110

Carlson KW, Nawy SS, Wei ET, Sadee W, Filov VA, Rezsova VV, Slominski A, Quillan JM (2001) Inhibition of mouse melanoma cell proliferation by corticotropin-releasing hormone and its analogs. Anticancer Res 21:1173-1179

Fekete EM, Zorrilla EP (2007) Physiology, pharmacology, and therapeutic relevance of urocortins in mammals: ancient CRF paralogs. Front Neuroendocrinol 28:1-27

Fekete C, Sarkar S, Rand WM, Harney JW, Emerson CH, Bianco AC, Beck-Sickinger A, Lechan RM (2002) Neuropeptide Y1 and Y5 receptors mediate the effects of neuropeptide $\mathrm{Y}$ on the hypothalamic-pituitary-thyroid axis. Endocrinology 143: 4513-4519

Hinkle RT, Donnelly E, Cody DB, Bauer MB, Sheldon RJ, Isfort RJ (2004) Corticotropin releasing factor 2 receptor agonists reduce the denervation-induced loss of rat skeletal muscle mass and force and increase non-atrophying skeletal muscle mass and force. J Muscle Res Cell Motil 25:539-547

Hughes FJ, Turner W, Belibasakis G, Martuscelli G (2006) Effects of growth factors and cytokines on osteoblast differentiation. Periodontology 2000 41:48-72

Ikeda K, Tojo K, Oki Y, Nakao K (2002) Urocortin has cellproliferative effects on cardiac non-myocytes. Life Sci 71: 1929-1938
Isfort RJ, Wang F, Tscheiner M, Donnelly E, Bauer MB, Lefever F, Hinkle RT, Mazur AW (2005) Discovery of corticotropin releasing factor 2 receptor selective sauvagine analogues for treatment of skeletal muscle atrophy. J Med Chem 48:262-265

Kageyama K, Hanada K, Nigawara T, Moriyama T, Terui K, Sakihara S, Suda T (2006) Urocortin induces interleukin-6 gene expression via cyclooxygenase-2 activity in aortic smooth muscle cells. Endocrinology 147:4454-4462

Kimura Y, Takahashi K, Totsune K, Muramatsu Y, Kaneko C, Darnel AD, Suzuki T, Ebina M, Nukiwa T, Sasano H (2002) Expression of urocortin and corticotropin-releasing factor receptor subtypes in the human heart. J Clin Endocrinol Metab 87:340-346

Kotz CM, Wang C, Levine AS, Billington CJ (2002) Urocortin in the hypothalamic PVN increases leptin and affects uncoupling proteins-1 and -3 in rats. Am J Physiol Regul Integr Comp Physiol 282:R546-R551

Latchman DS (2002) Urocortin. Int J Biochem Cell Biol 34:907-910

Marie PJ, Sabbagh A, de Vernejoul MC, Lomri A (1989) Osteocalcin and deoxyribonucleic acid synthesis in vitro and histomorphometric indices of bone formation in postmenopausal osteoporosis. J Clin Endocrinol Metab 69:272-279

Marie PJ, Hott M, Launay JM, Graulet AM, Gueris J (1993) In vitro production of cytokines by bone surface-derived osteoblastic cells in normal and osteoporotic postmenopausal women: relationship with cell proliferation. J Clin Endocrinol Metab $77: 824-830$

Nazarloo HP, Buttrick PM, Saadat H, Dunn AJ (2006) The roles of corticotropin-releasing factor-related peptides and their receptors in the cardiovascular system. Curr Protein Pept Sci 7:229-239

Owen TA, Aronow M, Shalhoub V, Barone LM, Wilming L, Tassinari MS, Kennedy MB, Pockwinse S, Lian JB, Stein GS (1990) Progressive development of the rat osteoblast phenotype in vitro: reciprocal relationships in expression of genes associated with osteoblast proliferation and differentiation during formation of the bone extracellular matrix. J Cell Physiol 143:420-430

Ponce ML, Koelling S, Kluever A, Heinemann DE, Miosge N, Wulf G, Frosch KH, Schutze N, Hufner M, Siggelkow H (2008) Coexpression of osteogenic and adipogenic differentiation markers in selected subpopulations of primary human mesenchymal progenitor cells. J Cell Biochem 104:1342-1355

Rickard DJ, Sullivan TA, Shenker BJ, Leboy PS, Kazhdan I (1994) Induction of rapid osteoblast differentiation in rat bone marrow stromal cell cultures by dexamethasone and BMP-2. Dev Biol 161:218-228

Sehringer B, Zahradnik HP, Simon M, Ziegler R, Noethling C, Schaefer WR (2004) mRNA expression profiles for corticotrophin-releasing hormone, urocortin, CRH-binding protein and $\mathrm{CRH}$ receptors in human term gestational tissues determined by real-time quantitative RT-PCR. J Mol Endocrinol 32:339-348

Siggelkow H, Rebenstorff K, Kurre W, Niedhart C, Engel I, Schulz H, Atkinson MJ, Hufner M (1999) Development of the osteoblast phenotype in primary human osteoblasts in culture: comparison with rat calvarial cells in osteoblast differentiation. J Cell Biochem 75:22-35

Siggelkow H, Eidner T, Lehmann G, Viereck V, Raddatz D, Munzel U, Hein G, Hufner M (2003) Cytokines, osteoprotegerin, and RANKL in vitro and histomorphometric indices of bone turnover in patients with different bone diseases. J Bone Miner Res 18:529-538

Siggelkow H, Schmidt E, Hennies B, Hufner M (2004) Evidence of downregulation of matrix extracellular phosphoglycoprotein during terminal differentiation in human osteoblasts. Bone 35:570-576

Slominski A, Wortsman J (2000) Neuroendocrinology of the skin. Endocr Rev 21:457-487 
Slominski A, Zbytek B, Zmijewski M, Slominski RM, Kauser S, Wortsman J, Tobin DJ (2006) Corticotropin releasing hormone and the skin. Front Biosci 11:2230-2248

Tezval H, Jurk S, Atschekzei F, Becker JU, Jahn O, Serth J, Kuczyk MA (2009a) Urocortin and corticotropin-releasing factor receptor 2 in human renal cell carcinoma: disruption of an endogenous inhibitor of angiogenesis and proliferation. World J Urol 27(6):825-830

Tezval H, Jurk S, Atschekzei F, Serth J, Kuczyk MA, Merseburger AS (2009b) The involvement of altered corticotropin releasing factor receptor 2 expression in prostate cancer due to alteration of anti-angiogenic signaling pathways. Prostate 69(4):443-448
Vaughan J, Donaldson C, Bittencourt J, Perrin MH, Lewis K, Sutton S, Chan R, Turnbull AV, Lovejoy D, Rivier C et al (1995) Urocortin, a mammalian neuropeptide related to fish urotensin I and to corticotropin-releasing factor. Nature 378:287-292

Viereck V, Siggelkow H, Tauber S, Raddatz D, Schutze N, Hufner M (2002) Differential regulation of Cbfa1/Runx2 and osteocalcin gene expression by vitamin-D3, dexamethasone, and local growth factors in primary human osteoblasts. J Cell Biochem 86:348-356

Xing L, Boyce BF (2005) Regulation of apoptosis in osteoclasts and osteoblastic cells. Biochem Biophys Res Commun 328: 709-720 